www.jmscr.igmpublication.org

Impact Factor (SJIF): 6.379

Index Copernicus Value: 71.58

ISSN (e)-2347-176x ISSN (p) 2455-0450

crossref DOI: https://dx.doi.org/10.18535/jmscr/v6i5.166

Journal Of Medical Science And Clinical Research

\title{
Prevalence of Diabetic peripheral neuropathy in Patna city: an observational study done at tertiary diabetic clinic at Patna (Eastern India) by measuring Vibratory perception threshold
}

\author{
Author \\ Dr Surendra Prasad Singh \\ Asst. Professor, Department of Community Medicine, Patna Medical College \& Hospital, Patna, Bihar India \\ Corresponding Author \\ Dr Surendra Prasad Singh \\ 90, Malai Pagandi Chowk, Fit Road, Kankarbagh, Patna - 800020 India
}

\begin{abstract}
Objective: Increasing incidence of diabetic polyneuropathy motivated to conduct this observational study to estimate prevalence of the disease specially Patna city in eastern India.

Material \& Method: The present study was conducted on 720 type 2 diabetic subjects (580 male and 141 female) in the age group of 40 to 70 years. Vibratory perception threshold (VPT) was measured by Diabetic Neuropathy analyser which measures vibratory sensation quantitatively.

Result: Mean risk of Right foot VPT and Left foot VPT was considerably high in significant number of patients, which indicate the periodic check-up of diabetic neuropathy by conducting VPT in all groups of T2DM patients in daily clinical practice. More than 50\% patients were at mild risk and 33\% patients are at sever risk of diabetic neuropathy. Which indicates that despite in small no of patients and small tertiary set up, the statistical analysis indicate towards increasing prevalence of diabetic polyneuropathy among the patients od Patna city.

Conclusion: From this study we can conclude that all cases of diabetic patients irrespective of clinical symptoms of neuropathy should be advised to undergo VPT on regular intervals as a part of routine diabetic check-up which can help in the early diagnosis of neuropathy \& planning of future therapy to prevent progression of disease.
\end{abstract}

Keywords: DPN, VPT, DNS, Type 2 Diabetes mellitus, Biothesiometer.

\section{Introduction}

India has the largest number of type 2 diabetes mellitus (T2DM) cases in the world (40 million in 2007) and this is predicted to increase to 70 million by the year $2025^{1}$. Diabetic Polyneuropathy (DPN) is the most common of the heterogeneous group of diabetic neuropathies and contributes to 50 to $70 \%$ of nondramatic amputations. Diabetic peripheral neuropathy (DPN) is an important micro vascular complication of diabetes mellitus (DM). It is a major contributor to foot ulceration and lower limb amputation in persons with DM and have also a significant negative effect on patient's quality of life. This analysis and observation done in a tertiary diabetic clinic at Patna city by 
performing Vibration Perception Threshold in type 2 diabetes patients.

\section{Method}

Vibration perception threshold (VPT) testing was determined in 720 adults with type 2 diabetes mellitus with > 10 years of diabetes. Before taking sample informed consent was taken from the subjects and ethical clearance was taken from the institutional ethical clearance committee. Subjects were taken in the study only by taking following inclusion and exclusion criteria:-

\section{Inclusion Criteria}

- Subjects having history of type 2 diabetes mellitus with more than 10 years of duration.

- Subjects above 35 years of age.

\section{Exclusion Criteria}

- Subjects having limbsłgangrene.

- Subjects having neuropathy due to causes other than diabetes.

A vibration threshold of more than $25 \mathrm{~V}$ has a sensitivity of $83 \%$.The normal value of vibratory perception threshold as per the specification of instrument and the standardization of procedure was 14.

BIOTHEZI-VPT is a biothesiometer from Kodys Medical Systems Pvt. Ltd. Chennai, India; the instrument measure the vibratory perception threshold (VPT) at various sites on plantar foot quantifies the loss of sensation. Increase in VPT means diminished sensation. The biothesiometer probe, which vibrates at amplitude proportional to the square of the applied voltage, was applied perpendicular to the test site with a constant and firm pressure. Patients were initially explained the sensation by holding the probe against the distal palmar surface of hand. VPT was then measured at the distal plantar surface of great toe of both the legs. The mean of three records was taken and neuropathy was diagnosed. The study was carried out as per Dipasaha et al. $^{3}$, at an average of 6 specific points in both feet: - great toe, 1 st metatarsal, 3rd metatarsal, 5th metatarsal, instep and heel. After proper explanation about the probe and the vibrations, the patient is informed to concentrate on feet. Symptoms of diabetic neuropathy were scored with the Diabetic Neuropathy Symptom (DNS) score and a score $\geq$ 1 was considered significant. VPT was measured with a biothesiometer by a single observer. During recording, the voltage was increased from 0 to 50 volts. The instrument specific normative data found after studying 720 controls were Normal up to 10 volt; Grade I - 10 to 15 Volt, Grade II 16 to 25 and Grade III Volt - >25 volt.

\section{Statistical Analysis}

Statistical software (Graph Pad Prism5; version 5.01) was used for analysis. Statistical tests were considered significant if P-value was $<0.05$ at confidence interval of $95 \%$.

\section{Result}

The DNS and DNE scores are essential for the clinical evaluation of peripheral neuropathy in patients with diabetes. There were several study carried out by various author by DNS measurements. The study was carried out from August 2016 to April 2018 at a tertiary diabetic clinic in Patna.

The out patients were screened for DNS and they were known diabetes of type2. The patients were screened for various parameters (Table: 1) like age, sex, duration of diabetes, Physical parameters like BMI; blood sugar like FPG, PPPG and HbAlc; and VPT in right and left leg in the areas of great toe 1st metatarsal, 3rd metatarsal, 5th metatarsal, instep and heel. 
Table 1: Characteristics of the study population

\begin{tabular}{|l|c|c|}
\hline \multicolumn{3}{|l|}{ Number of Subject N $\mathbf{7 2 0}$} \\
\hline Characteristic & Mean results & P Value \\
\hline Age (yr) & $50.29 \pm 11.93$ & 0.0567 \\
\hline Sex (M:F) & $22.5 \pm 0.71$ & 0.5 \\
\hline Duration of DM (yr) & $5.68 \pm 5.07$ & 0.892 \\
\hline BMI (kg/m2) & $24.85 \pm 5.85$ & 0.0721 \\
\hline FPG (mg/dl) & $145.93 \pm 59.28$ & 0.562 \\
\hline PPPG (mg/dl) & $202.62 \pm 100.2$ & 0.731 \\
\hline HbA1c (\%) & $7.8 \pm 0.7$ & 0.569 \\
\hline Right leg (v) & $17.79 \pm 7.2$ & 0.826 \\
\hline Left leg (v) & $18.78 \pm 7.01$ & 0.581 \\
\hline Great toe (v) & $19.45 \pm 6.5$ & 0.089 \\
\hline 1st metatarsal (v) & $16.59 \pm 26.23$ & 0.982 \\
\hline 3rd metatarsal (v) & $15.4 \pm 8.9$ & 0.418 \\
\hline 5th metatarsal (v) & $17.7 \pm 7.0$ & 0.513 \\
\hline Instep (v) & $16.7 \pm 86.52$ & 0.491 \\
\hline Heel (v) & $17.3 \pm 9.35$ & 0.732 \\
\hline
\end{tabular}

Mean risk of Right foot VPT and Left foot VPT was considerably high in significant number of patients, which indicate the periodic check-up of diabetic neuropathy by conducting VPT in all group of T2DM patients in daily clinical practice. More than $50 \%$ patients were at mild risk and $33 \%$ patients are at sever risk of diabetic neuropathy. Which indicates that despite in small no of patients and small tertiary set up, the statistical analysis indicate towards increasing prevalence of diabetic polyneuropathy among the patients od Patna city.

Table 2: DNS and DNE score

\begin{tabular}{|l|c|c|c|c|}
\hline $\begin{array}{l}\text { DNS } \\
\text { score }\end{array}$ & Observations Volt & Inference & $\begin{array}{c}\text { DNE } \\
\text { score }\end{array}$ & $\begin{array}{c}\text { \% of DNE } \\
\text { score }\end{array}$ \\
\hline Normal & up to 10 Volt & Normal & 85 & 11.8 \\
\hline Grade I & 10 to 16 Volt & Mild & 405 & 56.25 \\
\hline Grade II & 16 to 25 Volt & Moderately severe & 191 & 26.53 \\
\hline Grade III & $>25$ Volt. & Extremely severe & 39 & 5.42 \\
\hline
\end{tabular}

In our observational trial it has been observed that the risk of developing diabetic neuropathy was in increased stage mainly because of higher number of obese patients. In several trial it has been confirmed that obesity is one of the major risk factor for diabetes and even in T2DM patient's obesity increases the risk of diabetic macro and microvascvular complications.

\begin{tabular}{|l|c|c|c|}
\hline SI No & BMI & No of Patients & \% of Patients \\
\hline 1 & $\geq 25 \mathrm{Kg} / \mathrm{m} 2$ & 480 & 67 \\
\hline 2 & $\leq 25 \mathrm{Kg} / \mathrm{m} 2$ & 240 & 33 \\
\hline
\end{tabular}

\section{Discussion}

Diabetes mellitus is now established as one of the leading causes of morbidity and mortality throughout the world. Most of these ill-effects on health can be almost entirely attributed to longterm complications of diabetes. Neuropathy is among the most common and troublesome complications that affect diabetic patients. It is not only a cause of increased morbidity, but also mortality due to its autonomic component. In over half of the patients, neuropathy may be silent and only come to attention when the patient develops a diabetic foot.

Early lesions of diabetic neuropathy may arise from exposure of peripheral nerves to hyperglycaemia. The glucose uptake into peripheral nerve is insulin independent; therefore it is proportionate to ambient blood glucose concentration. The excess glucose is shunted into polyol pathway where the glucose is converted into sorbitol and fructose by the enzyme aldose reductase and sorbitol dehydrogenase together with deficiencies of myoinositol and diacylglycerol all may combine as potent metabolic factors responsible for structural breakdown of nerves and slowed conduction velocity. Use of the vibration perception threshold (VPT) is a simple way of detecting large-fiber dysfunction. Therefore the diabetic neuropathy can be detected by the use of Vibration perception threshold (VPT) measured by Biothesiometer. 
The history and physical examination remains the most fundamental tool to evaluate DPN. This observation clearly point out that if duration of diabetes is more than 5 years and Fasting Blood Glucose (FBG), Post Prandial Blood Glucose and HbA1c is not controlled as per ADA guideline then the chances of losing motor senses were always in higher side. This established a essentiality of routine check-up of VPT irrespective of duration and glycemic control. VPT may provide important, clinically meaningful information about large nerve fiber dysfunction in diabetes. The neurological impairments associated with large fiber neuropathy account for $80 \%$ of the morbidity associated with DSPN ${ }^{6}$. Abnormal VPT values have been shown to predict the longterm complications of ulceration and amputation ${ }^{7}$. Interestingly even in diabetic patient without clinical neuropathy, $60 \%$ show grade I severity with VPT testing. So, maximum patients with clinical neuropathy show grade II severity with vibration perception threshold. But they did not find any significant difference between the symptomatic and asymptomatic cases.

The present study results shows statistically significant positive correlation between the duration of diabetes and the vibratory perception threshold and also shows negative correlation between the age of the individual and the VPT.

\section{Conclusion}

From this study we can conclude that all cases of diabetic patients irrespective of clinical symptoms of neuropathy should be advised to undergo VPT on regular intervals as a part of routine diabetic check-up which can help in the early diagnosis of neuropathy \& planning of future therapy to prevent progression of disease.

\section{Disclosure}

The authors report no conflicts of interest in this work. No funding sources.

\section{References}

1. Sicree R, Shaw J, Zimmet P. Diabetes and impaired glucose tolerance. In D. Gan (Ed)., Diabetes Atlas. International Diabetes Federation. Third Edition, Published by International Diabetes Federation, Belgium, 2006, pp.15 -103.

2. Dipasaha, Kaushik saha and P. K. Dasgupta. Vibration sense impairment in diabetes mellitus. Indian $\mathbf{J}$ Physiol Pharmacol, 2011; 55 (4): 381-383.

3. SK Bhadada, RK Sahay, VP Jyotsna, JK Agrawal Diabetic Neuropathy: Current Concepts. Journal, Indian Academy of Clinical Medicine. 2001;2(4): 305-318.

4. OC Oguejiofor, CU Odenigbo, CBN Oguejiofor. Evaluation of the effect of duration of diabetes mellitus on peripheral neuropathy using the United Kingdom screening test scoring system, Biothesiometry and aesthesiometry. Nigerian Journal of Clinical Practice. Sept. 2010 Vol. 13(3): 240-247.

5. Boulton AJ, Vinik AI, Arezzo JC, Bril V, Feldman EL, Freeman R, Malik RA, Maser RE, Sosenko JM, Ziegler D, American Diabetes Association. Diabetic neuropathies: a statement from the American Diabetes Association. Diabetes Care 2005;28:956 -962

6. Malik RA, Tesfaye S, Newrick PG, Walker D, Rajbhandari SM, Siddique I, Sharma AK, Boulton AJ, King RH, Thomas PK, Ward JD. Sural nerve pathology in diabetic patients with minimal but progressive neuropathy. Diabetologia 2005;48:578 -585. 